\title{
Tree-Ring Growth Trends of Abies alba Mill: Possible Adaptations to Climate Change in Marginal Populations of Central Italy
}

\author{
Gianluigi Mazza ${ }^{*}, 1$, Valeria Gallucci ${ }^{2}$, Maria Chiara Manetti ${ }^{1}$ and Carlo Urbinati ${ }^{2}$ \\ ${ }^{I}$ Consiglio per la Ricerca e la sperimentazione in Agricoltura - Forestry Research Centre (CRA-SEL), Viale S. \\ Margherita 80, 52100 Arezzo, Italy \\ ${ }^{2}$ Department of Agricultural, Food and Environmental Sciences, Marche Polytechnic University, Via Brecce bianche, \\ 60121 Ancona, Italy
}

\begin{abstract}
A dendroclimatic analysis was used to assess the climate-growth relationships of Abies alba Mill. over the last century in marginal populations of Central Italy. Tree-ring cores were collected in five mixed silver fir forests at low and high-elevation sites of the Apennines range in Tuscany and Marches. Regular and moving correlations functions were applied to tree-ring width series and monthly climate gridded data.

Principal component analysis displayed groups of chronologies with similar growth patterns, discriminating for altitude and geographical location. Climate-growth relationships showed the positive influence of late-spring and summer precipitations and the negative effect of summer temperatures. Stands growing within the optimal altitude range for the species showed a positive and a decreasing negative influence of spring and summer temperatures, respectively. At the highest site $(1375 \mathrm{~m}$ asl) the positive effect of previous year spring-summer precipitation and summer temperature of both previous and current year became scarce or null. Results suggest that the shifting influence of summer precipitation on tree-rings growth from July to August of the previous year is a possible response of silver fir to the significant reduction of spring precipitation and general temperature increase throughout the 20th century.
\end{abstract}

Keywords: Climate change, dendroclimatology, forestry, LIFE Resilfor, Silver fir, tree-rings.

\section{INTRODUCTION}

In Italy forests with silver fir (Abies alba Mill.) are widespread across the Alps, but more scattered along the Apennines, due to post-glacial climate dynamics and anthropic action. Climate change, increasing conservation constraints, abandonment of mountain areas have considerably contributed to reduce the value of fir timber in the Apennines. Especially in Natura2000 sites management is often based on stand natural development causing dense canopy cover and lack of natural regeneration. Silver fir conservation requires a review of traditional silviculture with more attention to species adaptation to non-stationary environmental conditions. The "Resilfor" Life+ Nature project was set up for the conservation and restoration of native Abies alba populations in beech forests of central Italy. Silvicultural treatments, based on adaptive and sustainable forest management, included selective thinning in the dominant beech layer and plantation of fenced micro-arboreta with native silver fir.

This study aimed: i) to assess the radial growth dynamics of silver fir in 5 different sites, ii) to detect its climate sensitivity and response stationarity through time in order to calibrate active management.

*Address correspondence to this author at the Viale S. Margherita 80, I52100 Arezzo (Italy) / Consiglio per la ricerca e la, Sperimentazione in agricoltura - Forestry Research Centre, Italy;

Tel: +39 0575 353021; Fax: +39 0575353490 ;

E-mails: gianluigi.mazza@entecra.it, gianluigi_mazza@virgilio.it

\section{MATERIALS AND METHODS}

Study sites are located at five populations of mixed beech- fir mountain forests in Central Italy, all included as a priority habitat in Sites of Community Interest (SCI). Three are in Tuscany: Verna (VRN), Camaldoli (CAM) and Pigelleto (PGL) and two in the Marches: Fonte Abeti (FAB) and Colle Abete (CAB) (Fig. 1). CAM, FAB are mainly pure regular even-aged high forests, VRN is a stratified beechmaple-fir forest, PGL is an irregular mixed hardwood forest and $\mathrm{CAB}$ is a stored beech coppice in conversion to high forest, with silver fir in intermediate or co-dominant layer. At each site, two cores per tree were extracted with a 5-mm diameter increment borer at breast height on the cross-sides of healthy, possibly dominant, straight trees; each ring-width series was checked for crossdating and 5 mean chronologies were built from a total of 325 tree-ring series and 193 trees. To remove low-frequency variance, each tree-ring series was standardized with a double detrending procedure with software ARSTAN: a negative exponential curve to remove trends due to the increasing tree circumference and a spline function with a $50 \%$ frequency response (cut-off) of 10 years to emphasize higher interannual frequency variance [1].

Common growth patterns were explored by principal components (PCA) and hierarchical cluster analysis (HCA) of the tree-ring chronologies, to assess the shared variance of the common interval covered by all the series. 

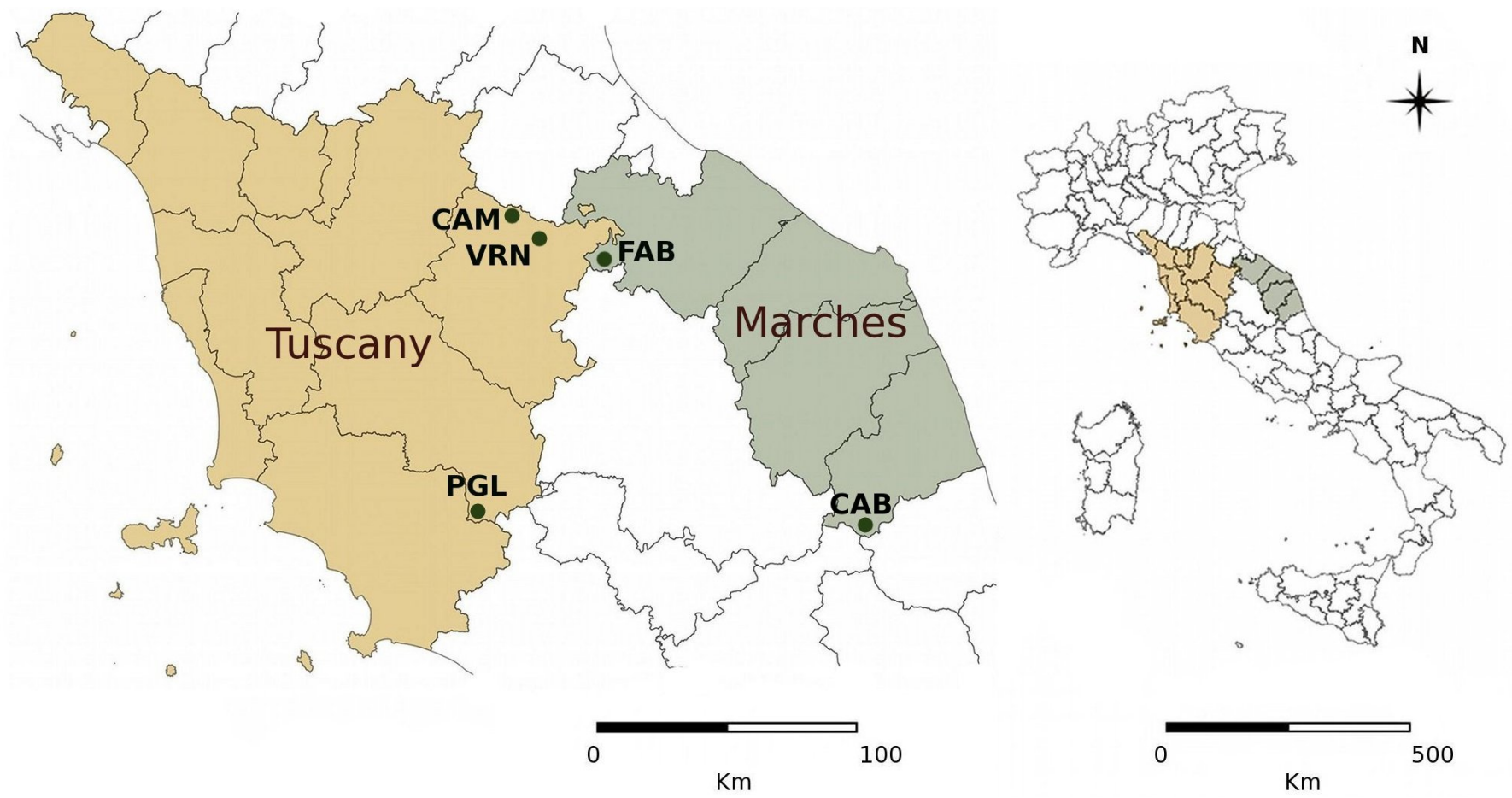

Fig. (1). Location of the sampled forest stands. Site codes are shown in Table 1.

Due to the lack of suitable meteorological stations we used climate data derived from CRU TS 3.1 dataset. We selected the closest grid point to each site and the complete monthly temperature and precipitation time series from 1901 to 2009. To assess the presence of climatic trends, the MannKendall $(\tau)$ non-parametric test was applied [2].

The influence of climate on tree-ring growth was investigated using mean (CF) and moving correlation functions (MCF) [3], based on Pearson's correlation coefficients and independent monthly climate variables sequenced from May of the year prior to ring formation $(t-1)$ to November of the year of growth (t). Pearson's correlation coefficients were tested for significance using the $95 \%$ percentile range method after a bootstrap process with 1000 replications. With MCF we applied a 50-year interval progressively shifted over time to compute the correlation coefficients for the same monthly variables previously used. Climate-growth relationships were performed using "bootRes" package in R program.

\section{RESULTS}

Length of chronologies spans from 98 to 210 years, with mean tree-ring width ranging from 1.55 (SD 1.02) of $\mathrm{CAB}$ to
$3.70 \mathrm{~mm}$ (2.28) of CAM. Mean sensitivity (MS) varies from $0.20(\mathrm{CAB})$ to $0.26(\mathrm{PGL})$ and ranges near the threshold between complacence and sensitivity. First order autocorrelation prior standardisation (AC) is rather high, but suitably removed in indexed series (ACstd). The average correlation between series within each population (rbar) is higher at VRN and CAB (Table 1).

Principal component analysis of the indexed mean chronologies featured distinct spatial distribution: PGL and $\mathrm{CAB}$ are isolated, VRN, CAM and FAB form a small group. The first two principal components explained $63.2 \%$ of the tree-ring growth variation. Similarly the hierarchical cluster analysis showed a clear separation between stands, possibly discriminating for altitude and geographical location.

Climate-growth response profiles (Fig. 2) reflect the results obtained with multivariate analysis, showing a more similar behaviour of silver fir at VRN, CAM and FAB chronologies, and very low or absent patterns at the other two sites. Similarity is more evident especially for late spring - summer precipitations of the previous year ( $t-1)$. At the three sites summer maximum temperatures exert a negative and contrasting influence over time on fir growth: at CAM

Table 1. Descriptive Statistics of the 5 Silver Fir Chronologies. MRW (Mean Ring Width); SD (Standard Deviation); AC (First Order Autocorrelation) of Raw and of Standardized Series (AC Std); Rbar (Mean Interserial Correlation)

\begin{tabular}{|c|c|c|c|c|c|c|c|c|c|}
\hline Site & Elevation (m asl) & Lat - Long & Time Span (nºf years) & MRW (mm) & SD & MS & AC & AC std & Rbar \\
\hline \hline VRN & 1160 & $43^{\circ} 42^{\prime}-11^{\circ} 55^{\prime}$ & $1845-2010(166)$ & 2.60 & 1.59 & 0.25 & 0.86 & -0.01 & 0.47 \\
\hline CAM & 1120 & $43^{\circ} 47^{\prime}-11^{\circ} 49^{\prime}$ & $1862-1998(137)$ & 3.70 & 2.28 & 0.22 & 0.89 & -0.04 & 0.27 \\
\hline FAB & 1000 & $43^{\circ} 36^{\prime}-12^{\circ} 14^{\prime}$ & $1892-2010(119)$ & 2.63 & 1.22 & 0.23 & 0.79 & -0.02 & 0.28 \\
\hline PGL & 770 & $42^{\circ} 48^{\prime}-11^{\circ} 39^{\prime}$ & $1913-2010(98)$ & 2.17 & 1.38 & 0.26 & 0.84 & -0.03 & 0.34 \\
\hline CAB & 1350 & $42^{\circ} 43^{\prime}-13^{\circ} 22^{\prime}$ & $1800-2010(210)$ & 1.55 & 1.02 & 0.20 & 0.86 & -0.01 & 0.41 \\
\hline
\end{tabular}




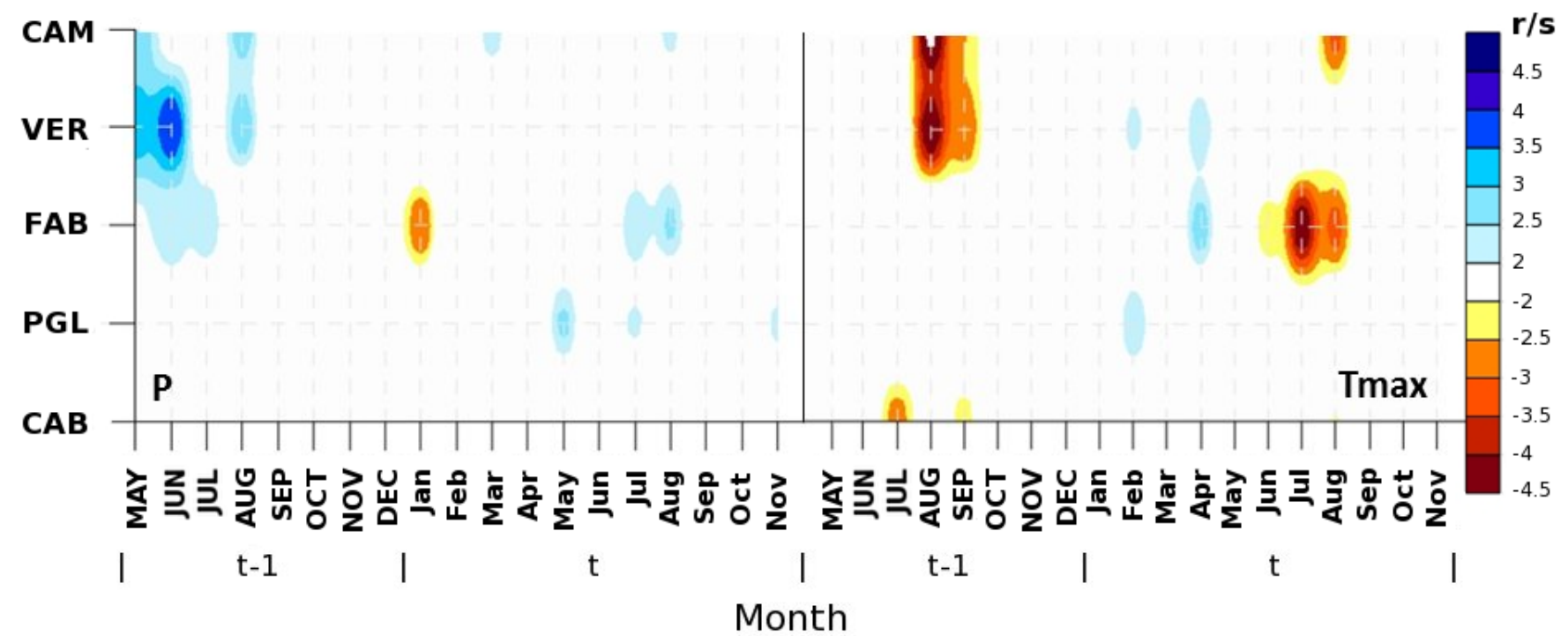

Fig. (2). Contour plots of the correlation functions between tree-ring indexed chronologies and total monthly precipitation and mean monthly maximum temperatures from May ( $\mathrm{t}-1)$ to November $(\mathrm{t})$. Values above $|2|$ are significant at $\mathrm{p}<0.05$.

and VRN on the year prior the ring formation ( $t-1)$, at FAB on the current year $(\mathrm{t})$. The moving correlation functions profiles confirm the presence of geographical variability among sites, excluding PGL where no significant responses were observed (Fig. 3). Although all sites are positively influenced by spring-early summer precipitation of the previous year, sensitivity to precipitation increases with time at VRN, CAM, FAB chronologies whereas it decreases and disappears at $\mathrm{CAB}$. Moreover, for the group highlighted by PCA (VRN, CAM and FAB) a synchronous shift from July to August precipitation influence appears around 1950s.

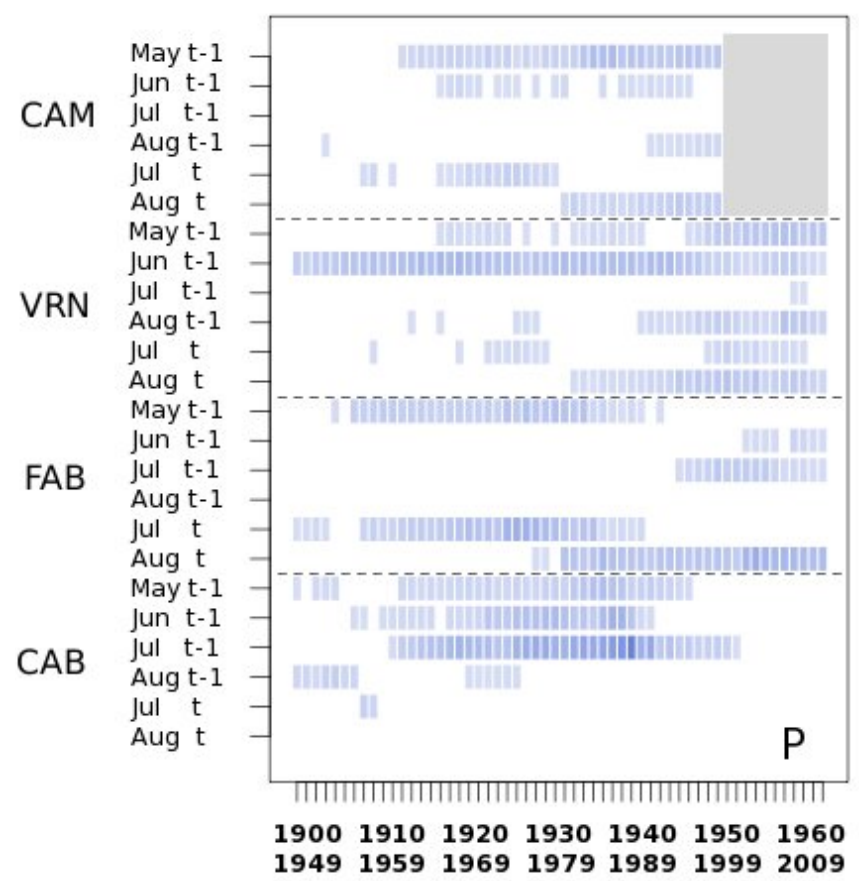

Summer temperatures (August in particular) maintain their negative significance through time at VRN, CAM and $\mathrm{FAB}$, while disappearing at $\mathrm{CAB}$.

\section{DISCUSSION}

Tree ring growth and climate responses variability of silver fir appear associated to geographic factors, (site location and altitude) however stand structure and previous forest management could also play a role although they have not been accounted for in this preliminary analysis. The

Fig. (3). Moving correlation functions for the same dataset as Fig. (2), computed using a 50-year moving window. Coefficients are represented, for each time window, in six and five cases on the y-axis for total monthly precipitation (P) and maximum monthly temperature (Tmax), respectively. Coloured boxes are significant $(\mathrm{p}<0.05)$ with the standard approach and are coded according to the chromatic scale at the right.

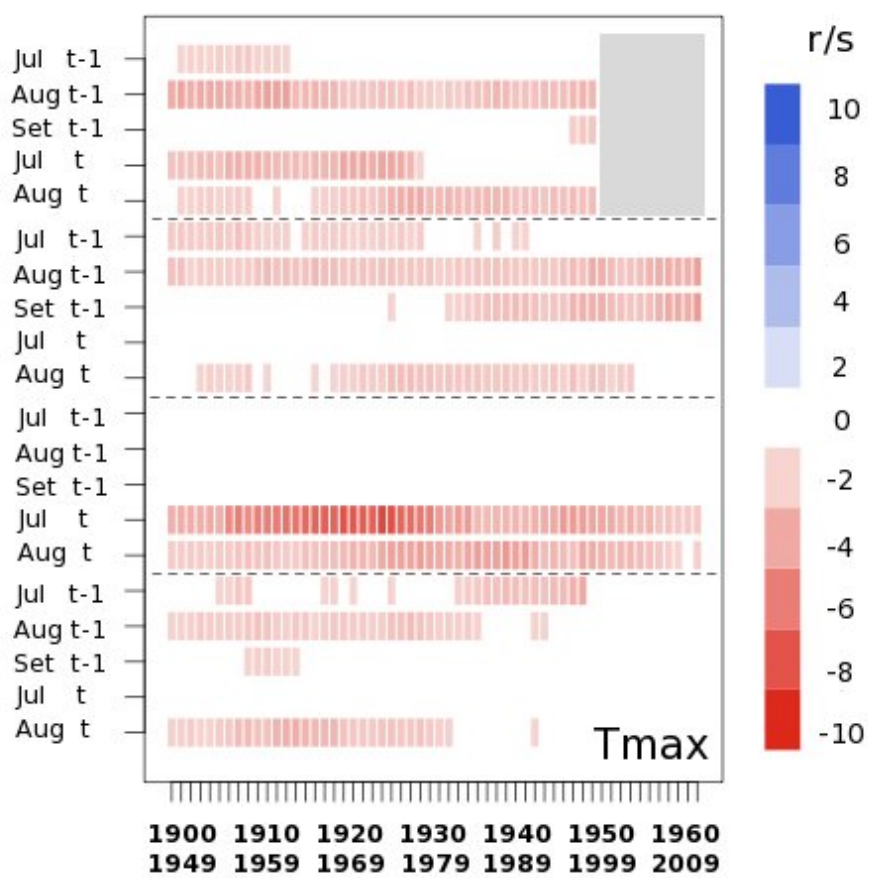


higher climate sensitivity of silver fir at FAB, especially during the year of ring formation $(\mathrm{t})$ is possibly related to the lower altitude and the southern aspect of the stand. Similarly the low sensitivity of $\mathrm{CAB}$ could be driven by the higher elevation and the northern slope location of the site. Less predictable is the low or absent sensitivity at PGL, at low elevation, where chronological and spatial structure of the stand could affect results. Summer months are the most crucial to silver fir, featuring in some sites a shifting sensitivity prior or during the year of ring formation according to its capacity to accumulate starch for early development in the following year.

Changes of growth responses to climate over time, suggest a significant influence of the enhanced warming and the reduction of spring precipitation over the last decades. However silver fir reveals different behaviours: in less favourable sites the sensitivity increases or shifts between the same months of the on-going or previous year of ring formation; in more favourable ones the sensitivity decreases up to disappearance, as observed for the same species in other sites of Italy [4].

Silver fir is a climate-sensitive tree species, but its diverse responses are not a mere effect of site suitability. Stand structure and management should be taken into account since they can influence the microclimate and therefore growth dynamics. Genetic provenance could also be considered as a possible driver for variability; the genotype analysis currently performed within the project would provide important information at this regard.
These results, although preliminary, show distinct patterns of silver fir on the eastern and western slopes of central Apennines. Further analysis on high-frequency climatic signals would provide more suitable information to be used for calibrating silvicultural treatments for conservation of sensitive ecosystems and tree species in mountain areas.

\section{CONFLICT OF INTEREST}

The authors confirm that this article content has no conflict of interest.

\section{ACKNOWLEDGEMENTS}

Declared none.

\section{REFERENCES}

[1] Cook ER, Peters K. The smoothing spline: a new approach to standardizing forest interior tree-ring width series for dendroclimatic studies. Tree-Ring Bull 1981; 41: 45-53.

[2] Brunetti $M$, Maugeri $M$, Monti F, Nanni T. Temperature and precipitation in Italy in the last two centuries from homogenised instrumental time series. Int J Climatol 2006; 26: 345-81.

[3] Fritts HC, Eds. Tree Rings and Climate. New York: Academic Press 1976.

[4] Carrer M, Nola P, Motta R, Urbinati C. Contrasting tree-ring growth to climate responses of Abies alba toward the southern limit of its distribution area. Oikos, 2010; 119: 1515-25. 